\title{
Taurine Supplementation of a Premature Formula Improves Fat Absorption in Preterm Infants
}

\author{
NARMER F. GALEANO, PAULINE DARLING, GUY LEPAGE, CLAUDIE LEROY, \\ SYLVIE COLLET, ROBERT GIGUĖRE, AND CLAUDE C. ROY \\ Pediatric Gastroenterology Unit, Department of Pediatrics, Hôpital Ste-Justine and le Centre Hospitalier \\ Universitaire de Sherbrooke, Universities of Montreal and of Sherbrooke, Quebec. Canada
}

\begin{abstract}
The predominance of taurine (Tau) conjugated over glycine conjugated bile acids in infants fed human milk as opposed to those on formulas without added Tau could account for a more complete absorption of fat. Fifteen low birth weight infants were randomized to either Enfamil Premature or to Enfamil Premature added with $40 \mu \mathrm{mol} / \mathrm{dl}$ of Tau and compared to a third group made up of nine low birth weight infants fed their own mother's preterm milk. Formulas and human milk were fed according to tolerance and constituted the sole nutrition for 3 months. A metabolic study was carried out at 3 wk of age and control of growth was done periodically. Urinary Tau excretion $(\mu \mathrm{mol} / \mathrm{dl})$ was very low $(p<0.001)$ in the group fed Enfamil Premature $(0.3 \pm 0.1)$ when compared to the values obtained in infants supplemented with Tau (51.6 \pm 12.5) and in those on human milk $(36.3 \pm 7.9)$. Infants supplemented with Tau $(92.5 \pm 1.2)$ had a coefficient of fat absorption which was higher $(p<0.05)$ than the unsupplemented group $(87.5 \pm 7.9)$ and comparable to the human milk-fed group $(91.6 \pm 1.4)$. The effect was more pronounced on the saturated fatty acids and varied inversely with their individual water solubility. There was no effect of Tau on nitrogen retention and growth was identical in the three groups. These data show that the addition of Tau to formula had no effect on growth but improved the absorption of fat especially saturated fatty acids which require higher concentrations of bile acids to form mixed micelles. (Pediatr Res 22: 67-71, 1987)
\end{abstract}

In recent years, taurine has been the subject of increasing interest in view of its role on the retina, the central nervous system, liver function, and growth (1). Taurine fits the definition of a "conditionally essential" nutrient (2) because synthesizing capacity is limited and therefore needs cannot be met when dietary intake is inadequate or when losses are increased. The dietary dependency for taurine has been demonstrated in animal species $(3,4)$ and in man $(5)$. Two clinical studies have addressed the issue of increased needs in certain disease conditions $(6,7)$. Other reports $(8-10)$ have examined the role of supplemental taurine in preterm infants since the young of most species are thought to synthesize taurine less well than their adult conterparts (11).

The only well-characterized metabolic reaction of taurine is its conjugation with bile acids in the liver (1). Conjugation of bile acids is catalyzed by a single liver enzyme, n-acetyl transfer-

Received October 6, 1986: accepted February 11, 1987

Correspondence Claude C. Roy, M.D., Pediatric GI Unit, Hôpital Ste-Justine. 3175 Côte Ste-Catherine Roar. Montreal, Quebec, Canada H3T 1C5.

Supported by Mead Johnson. Nutritional Division and by the Medical Research Council of Canada. ase, which has greater affinity for taurine than for glycine. As a result, the percentage of bile acids conjugated with taurine is closely correlated with the hepatic pool of taurine which in turn is dependent on the dietary intake (12). In contrast to human milk or taurine supplemented formula fed infants those who are offered formulas without added taurine have a predominance of glycine conjugated bile acids by 4 wk of age and low urinary taurine concentrations $(8-10,13)$.

There are theoretical advantages of tauroconjugates over glycoconjugates with regard to fat absorption. Tauroconjugates have a lower $\mathrm{pKa}$ and are therefore more likely to remain in solution when bicarbonate secretion is impaired through immaturity or defective exocrine pancreatic function (14). Furthermore tauroconjugates are mostly absorbed in the ileum (15) and could be more available to form mixed micelles with fat which escapes proximal absorption in preterm infants. This hypothesis appeared reasonable given the fact that preterm infants are fed large amounts of lipids and have low intraduodenal bile acid concentrations (16). However the two studies examining the effect of taurine-supplemented formulas have failed to show improved fat absorption $(8,10)$. Having recently reported that taurine supplements decrease fatty acid losses in cystic fibrosis patients with a high glycine/taurine ratio of conjugated bile acids (7) it was elected to conduct a further study.

\section{PATIENTS AND METHODS}

A total of 24 low birth weight infants were studied. Admission to the protocol required that they were free of major congenital abnormalities, hemolytic disease, hyaline membrane disease, and notable respiratory distress. As shown in Table 1, they were all appropriate for gestational age. The study protocol was approved by the Ethics Committee of Hôpital Ste-Justine, Montreal, Canada and informed consent was obtained from the parents.

Within the first $48 \mathrm{~h}$ of life, babies were randomized to Enfamil Premature Formula with or without added taurine at the concentration of $40 \mu \mathrm{mol} / \mathrm{dl}$ found in preterm milk (17). The macronutrient composition and caloric density of the formula is shown in Table 2 . A third group was made up of infants who were fed their own mothers' milk which was not heat treated. Routine care was provided. The large majority received intravenous therapy during the first few days and were gradually introduced to gavage feedings of formula or expressed human milk. The amounts given in this fashion depended on the individual baby's tolerance assessed clinically and determined by the amount of residual formula present in the stomach. None of the gavage-fed babies had nonnutritive sucking. Once bottle feeding was initiated, intake was regulated by the neonate.

A 3-day metabolic balance study was conducted on each infant during the 4 th wk of life (Table 1). Babies were placed on metabolic beds that permitted urine to flow into a glass bottle held on ice. Small plastic collecting bags were fitted around the 
Table 1. Clinical data of three groups of low birth wt infants $($ mean $\pm S D)$

\begin{tabular}{lccc}
\hline & $\begin{array}{c}\text { Enfamil } \\
\text { Premature } \\
(n=7)\end{array}$ & $\begin{array}{c}\text { Enfamil } \\
\text { Premature } \\
+ \text { taurine } \\
(n=8)\end{array}$ & $\begin{array}{c}\text { Preterm } \\
\text { human milk } \\
(n=9)\end{array}$ \\
\hline Birth wt (g) & 1436 & 1462 & 1428 \\
& \pm 152 & \pm 134 & \pm 125 \\
Gestational age & 32.3 & 32.4 & 31.0 \\
(wk) & \pm 1.6 & \pm 1.4 & \pm 1.2 \\
Ht index* & 0.95 & 0.95 & 0.97 \\
& \pm 0.07 & \pm 0.07 & \pm 0.05 \\
Wt index* & 0.98 & 0.97 & 0.99 \\
& \pm 0.04 & \pm 0.05 & \pm 0.03 \\
Head circumference & 0.98 & 0.95 & 0.95 \\
index* & \pm 0.05 & \pm 0.08 & \pm 0.05 \\
Age (days) when & 23 & 22 & 23 \\
metabolic study & \pm 4 & \pm 3 & \pm 4 \\
was carried out & & & \\
\hline * Reference 18. & & &
\end{tabular}

Table 2. Macronutrient composition and energy content of enfamil premature and of preterm human milk

\begin{tabular}{lcc}
\hline & $\begin{array}{c}\text { Enfamil } \\
\text { Premature }\end{array}$ & $\begin{array}{c}\text { Preterm } \\
\text { human milk* }\end{array}$ \\
\hline Nitrogen & $310 \mathrm{mg} / \mathrm{dl}$ & $250 \mathrm{mg} / \mathrm{dl}$ \\
Carbohydrates & $7.4 \mathrm{~g} / \mathrm{dl}$ & $6.5 \mathrm{~g} / \mathrm{dl} \dagger$ \\
Total fatty acids & $2.7 \mathrm{~g} / \mathrm{dl}$ & $3.94 \mathrm{~g} / \mathrm{dl}$ \\
$\quad$ Saturated & $13.2 \%$ & $35.6 \%$ \\
C14 & $4.3 \%$ & $7.0 \%$ \\
C16 & $7.1 \%$ & $20.0 \%$ \\
C18 & $1.7 \%$ & $7.6 \%$ \\
Unsaturated & $35.6 \%$ & $52.9 \%$ \\
Medium chain (C8, & $51.2 \%$ & $9.1 \%$ \\
$\quad$ C10, C12) & & \\
Total energy $\ddagger$ & $72 \mathrm{kcal} / \mathrm{dl}$ & $69 \mathrm{kcal} / \mathrm{dl}$ \\
\hline
\end{tabular}

* Reference 17.

$\dagger$ Reference 18.

$\ddagger$ Determined by bomb calorimetry.

anus to collect the stools which were immediately placed on dry ice kept at the bedside. Stools were collected between two carmine red markers consisting of $200 \mathrm{mg}$ of powder dissolved in $100 \mathrm{ml}$ of formula or human milk and given $72 \mathrm{~h}$ apart. A special nurse assistant was in attendance around the clock for babies who were on the metabolic bed. Babies were held while being fed and were handled just as frequently during the balance study through the use of plastic bags that were tied to the waist to prevent loss of urine. Infants were usually discharged when they reached a weight of $2000 \mathrm{~g}$ and continued to feed exclusively on the same formula or on human milk until 3 months of age. Growth measurements were monitored during the hospital stay and periodically into the follow-up clinic. A fixed headboard with sliding footboard was used to measure length while the same plastic-coated tape measure was used for recording occipitofrontal circumference. None of the babies initially recruited had to be dropped from the study protocol.

Weighed aliquots of formula, 24-h pools of human milk and 72-h stool homogenates were lyophilized and then submitted to calorimetric analysis (20). Losses of energy in the urine have been estimated from excreted urea and carbohydrate and correspond to $0.86 \mathrm{kcal} / \mathrm{kg} /$ day $(21)$. In the present study, an empirical figure of $0.9 \mathrm{kcal} / \mathrm{kg} /$ day was used to represent the urinary loss of energy. Metabolizable energy was calculated as the difference between energy intake and losses in the stools and with urine. Total nitrogen in urine, stool, formula, and human milk was measured by a modified Kjeldahl digestion procedure (22). Uri- nary taurine was determined by ion exchange chromatography on sulfonated polyestyrene beads linked to divinyl benzene, using an LKB Alpha Plus 4151 analyzer and a Hewlett Packard 3392 A integrator (23).

The technique used for fat was recently described by this laboratory (24). It does not require extraction prior to direct transesterification which is then followed by injection into an HP 5880 gas chromatograph using a $30-\mathrm{m}$ fused silica column wall coated with SP-2330. As an internal standard is added to fecal homogenate in this one-step reaction, precision of analysis is much higher. A more complete recovery of fatty acids from complex lipids is due to the fact that they are directly and completely freed from biological specimens during the transesterification procedure carried out at $100^{\circ} \mathrm{C}$ for $1 \mathrm{~h}$ and that there is no loss during the evaporation steps which are circumvented. The coefficient of variation for the different fatty acids varied from 0.4 to $2.0 \%$ with this methodology.

Analysis of variance was done using a priori orthogonal contrasts (25) involving comparison between the two formula groups and between the human milk group and the two formula groups taken together.

\section{RESULTS}

The effect of taurine supplementation on the urinary excretion of taurine was striking (Table 3 ). Whether expressed as a concentration or as total excretion over a 72 -h period, urinary taurine in the supplemented group was comparable to that of the human milk group and was more than a 100 -fold higher than that of neonates fed the formula without taurine.

The energy intake of the three groups differed significantly during the week of the metabolic balance study (Table 4). However, there was no difference in the percent of calories absorbed or in the metabolizable energy expressed as a percent of intake. Results of the fat balance study are shown in Table 5. There was no difference in the fat intake between the three groups. The percent fat absorption was higher in the taurine-supplemented infants and comparable to the group fed preterm human milk. Taurine had no effect on the absorption of medium-chain triglycerides but did improve that of unsaturated fatty acids. The data for the total saturated fatty acids show that preterm human milk had a distinct advantage over the two other groups. However, it is noted that taurine supplementation increased the

Table 3. Urinary taurine excretion (mean $\pm S E$ )

\begin{tabular}{cccc}
\hline & $\begin{array}{c}\text { Enfamil } \\
\text { Premature } \\
(n=7)\end{array}$ & $\begin{array}{c}\text { Enfamil } \\
\text { Premature } \\
+ \text { taurine } \\
(n=8)\end{array}$ & $\begin{array}{c}\text { Preterm } \\
\text { human milk } \\
(n=9)\end{array}$ \\
\hline$\mu \mathrm{mol} / \mathrm{dl}$ & $0.3^{*}$ & 51.6 & 36.3 \\
& \pm 0.1 & \pm 12.5 & \pm 7.9 \\
$\mu \mathrm{mol} / 72 \mathrm{~h}$ & $1.5^{*}$ & 196.9 & 147.1 \\
& \pm 0.7 & \pm 26.1 & \pm 38.5 \\
\hline
\end{tabular}

$* p<0.001$ Enfamil Premature versus Enfamil Premature + taurine

Table 4. Energy balance study (mean $\pm S E$ )

\begin{tabular}{|c|c|c|c|}
\hline & $\begin{array}{c}\text { Enfamil } \\
\text { Premature } \\
(n=7)\end{array}$ & $\begin{array}{c}\text { Enfamil } \\
\text { Premature } \\
+ \text { taurine } \\
(n=8)\end{array}$ & $\begin{array}{l}\text { Preterm } \\
\text { human milk } \\
\quad(n=9)\end{array}$ \\
\hline \multirow{4}{*}{$\begin{array}{l}\text { Intake }(\mathrm{kcal} / \mathrm{kg} / 24 \\
\text { h) } \\
\text { Energy absorbed (\%) }\end{array}$} & 148.8 & 130.6 & 115.6 \\
\hline & \pm 6.5 & $\pm 4.3^{*}$ & $\pm 5.2 \dagger$ \\
\hline & 90.9 & 92.4 & 89.1 \\
\hline & \pm 0.6 & \pm 1.1 & \pm 1.7 \\
\hline \multirow{2}{*}{$\begin{array}{l}\text { Metabolizable en- } \\
\text { ergy (\% of intake) }\end{array}$} & 90.1 & 91.8 & 88.6 \\
\hline & \pm 0.5 & \pm 1.1 & \pm 1.7 \\
\hline
\end{tabular}

${ }^{*} p<0.05$ Enfamil Premature + taurine versus Enfamil Premature. $\dagger p<0.01$ preterm human milk versus the two formula groups. 
Table 5. Effect of taurine supplementation on absorption (\%) of

\begin{tabular}{|c|c|c|c|}
\hline & $\begin{array}{c}\text { Enfamil } \\
\text { Premature } \\
(n=7)\end{array}$ & $\begin{array}{c}\text { Enfamil } \\
\text { Premature } \\
+ \text { taurine } \\
(n=8)\end{array}$ & $\begin{array}{c}\text { Preterm } \\
\text { human milk } \\
(n=9)\end{array}$ \\
\hline \multirow[t]{2}{*}{ Intake $(\mathrm{g} / 24 \mathrm{~h})$} & 10.9 & 8.9 & 11.1 \\
\hline & \pm 0.8 & \pm 0.6 & $\pm 0.8^{*}$ \\
\hline \multirow[t]{2}{*}{ Absorption(\%) } & 87.5 & 92.5 & 91.6 \\
\hline & \pm 0.8 & $\pm 1.2 \dagger$ & \pm 1.4 \\
\hline \multicolumn{4}{|l|}{$\begin{array}{l}\text { Saturated fatty } \\
\text { acids }\end{array}$} \\
\hline Total & $\begin{array}{r}61.5 \\
\pm 1.8\end{array}$ & $\begin{array}{l}71.3 \\
\pm 2.5 \dagger\end{array}$ & $\begin{array}{l}85.7 \\
\pm 2.5 \ddagger\end{array}$ \\
\hline $\mathrm{C} 14$ & $\begin{array}{r}77.2 \\
\pm 1.1\end{array}$ & $\begin{array}{l}81.2 \\
\pm 1.5 \S\end{array}$ & $\begin{array}{l}95.3 \\
\pm 1.0 \ddagger\end{array}$ \\
\hline $\mathrm{C} 16$ & $\begin{array}{r}59.2 \\
\pm 2.1\end{array}$ & $\begin{array}{l}69.9 \\
\pm 2.6 \S\end{array}$ & $\begin{array}{l}88.6 \\
\pm 1.7 \ddagger\end{array}$ \\
\hline $\mathrm{C} 18$ & $\begin{array}{r}40.8 \\
\pm 1.9\end{array}$ & $\begin{array}{l}55.1 \\
\pm 3.8 \S\end{array}$ & $\begin{array}{l}74.4 \\
\pm 3.2 \ddagger\end{array}$ \\
\hline Unsaturated fatty & 82.0 & $88.7^{\circ}$ & $92.6^{\circ}$ \\
\hline acids & \pm 1.5 & $\pm 1.7 \dagger$ & $\pm 2.0 \ddagger$ \\
\hline Medium-chain & 98.0 & 98.5 & 98.8 \\
\hline fatty acids & \pm 0.2 & \pm 0.3 & \pm 0.3 \\
\hline
\end{tabular}

* Based on the lipid concentration obtained from pools of 24-h collections (Ref. 17).

$+p<0.05$ Enfamil Premature + taurine versus Enfamil Premature.

$\ddagger p<0.01$ Preterm human milk versus the two formula groups.

$\S p<0.01$ Enfamil Premature + taurine versus Enfamil Premature.

absorption of saturated fatty acids of Enfamil Premature. The absorption of the three individual fatty acids, myristic (C14), palmitic (Cl6), and stearic (C18) accounting for more than $90 \%$ of saturated fatty acids in the formula increased by 4,10 , and $15 \%$, respectively.

Results of the nitrogen balance study are shown in Table 6. Babies on preterm human milk were at a disadvantage compared to the two formula groups; their nitrogen intake and retention were lower. However, when nitrogen retention was expressed as a percent of intake, there was no difference between the human milk group and the two others. Addition of taurine to the formula had no effect on overall nitrogen retention. Growth data (Table 7) obtained over a period of 3 months failed to demonstrate any advantage of taurine supplementation or any difference in the growth dynamics between the preterm human milk group and the two others.

\section{DISCUSSION}

This clinical study involving three groups of healthy preterm infants closely matched for birth weight, gestational age as well as for height, weight, and head circumference indices shows that taurine supplementation of a premature formula had a beneficial effect on fat absorption.

The overall decrease in the amount of fat sequestered in the stools did not lead to a significant sparing of metabolizable energy or to a change in nitrogen retention and growth. However, the percent of fat absorption was comparable to that achieved by the group of babies fed preterm human milk. This observation is of interest in view of all previous studies showing a significant advantage of nonheated mother's milk over formulas with regard to fatty acid absorption (26-30). Analysis revealed that $51.2 \%$ of the lipids in the formula were medium-chain triglycerides as opposed to an average of $9 \%$ in the samples of pooled preterm human milk. The fact that the medium-chain triglycerides were almost completely absorbed ( $>98 \%$ ) probably accounts for the observation that total fatty acid absorption did not differ between the taurine-supplemented and the human milk-fed groups.

The pattern of fatty acid excretion in response to preterm
Table 6. Nitrogen balance study (mean \pm SE)

\begin{tabular}{lccc}
\hline & $\begin{array}{c}\text { Enfamil } \\
\text { Premature } \\
(n=7)\end{array}$ & $\begin{array}{c}\text { Enfamil } \\
\text { Premature } \\
+ \text { taurine } \\
(n=8)\end{array}$ & $\begin{array}{c}\text { Preterm } \\
\text { human milk } \\
(n=9)\end{array}$ \\
\hline $\begin{array}{c}\text { Nitrogen intake }(\mathrm{mg} / \\
\mathrm{kg} / 24 \mathrm{~h})\end{array}$ & 665.6 & $578.2^{*}$ & $419.0+\ddagger$ \\
Nitrogen losses $(\mathrm{mg} /$ & \pm 26.8 & \pm 22.0 & \pm 28.9 \\
$\mathrm{~kg} / 24 \mathrm{~h})$ & & & \\
Fecal & 74.7 & 50.2 & 56.3 \\
& \pm 9.3 & \pm 4.9 & \pm 7.4 \\
Urinary & 94.0 & 89.0 & 73.2 \\
& \pm 8.9 & \pm 9.3 & \pm 8.6 \\
Nitrogen retention & 497.2 & 435.0 & $289.1 \ddagger$ \\
as mg/kg/24 h & \pm 21.5 & \pm 22.0 & \pm 21.8 \\
& 371.1 & 364.1 & $280.2 \ddagger$ \\
as mg/kg/day per & \pm 11.3 & \pm 7.1 & \pm 11.8 \\
$100 \mathrm{kcal}$ of me- & & & \\
tabolizable energy & 74.6 & 74.9 & 67.8 \\
as \% of intake & \pm 2.1 & \pm 1.4 & \pm 3.6 \\
\hline
\end{tabular}

${ }^{*} p<0.05$ Enfamil Premature + taurine versus Enfamil Premature.

+ Based on nitrogen concentration obtained from pools of 24 -h collections (Ref. 17)

$\ddagger p<0.01$ preterm human milk versus two formulas.

Table 7. Growth profile over period of 3 mo (mean $\pm S E)$

\begin{tabular}{lccc}
\hline & $\begin{array}{c}\text { Enfamil } \\
\text { Premature } \\
(n=7)\end{array}$ & $\begin{array}{c}\text { Enfamil } \\
\text { Premature } \\
+ \text { taurine } \\
(n=8)\end{array}$ & $\begin{array}{c}\text { Preterm } \\
\text { human milk } \\
(n=9)\end{array}$ \\
\hline $\mathrm{Wt}$ & & & \\
Birth (g) & 1436 & 1462 & 1428 \\
Time to regain & \pm 58 & \pm 47 & \pm 42 \\
birth wt (days) & 9.3 & 12.1 & 11.7 \\
From regained & 26.4 & \pm 1.6 & \pm 1.7 \\
birth weight to 3 & \pm 2.2 & 22.9 & 24.8 \\
mo (g/kg/day) & & \pm 2.1 & \pm 1.8 \\
Length & & & \\
Birth (cm) & 40.2 & 40.2 & 40.3 \\
& \pm 1.2 & \pm 0.8 & \pm 1.0 \\
From birth to 3 & 1.0 & 0.8 & 0.9 \\
mo (cm/wk) & \pm 0.1 & \pm 0.1 & \pm 0.1 \\
Head circumference & & & \\
Birth (cm) & 29.4 & 28.6 & 27.8 \\
& \pm 0.3 & \pm 0.6 & \pm 0.3 \\
From birth to 3 & 0.83 & 0.94 & 0.80 \\
mo (cm/wk) & \pm 0.10 & \pm 0.15 & \pm 0.02 \\
\hline
\end{tabular}

human milk and to the premature formula shows that the effect of taurine was more marked for the saturated fatty acids than for the unsaturates. An inverse relationship was recently reported between increasing chain length of saturated fatty acids and absorption (31). The present study confirms this finding and shows that taurine was particularly effective in promoting the absorption of palmitic and stearic acids identified as the major fecal fatty acids in neonates (32). It had less effect on the more polar unsaturated fatty acids largely made up of oleic and linoleic acids and none on the highly water soluble medium chain fatty acids.

The beneficial effect of taurine on fat absorption contrasts with the negative results reported in two studies $(8,10)$. In the first study, a lower concentration $(30 \mu \mathrm{mol} / \mathrm{dl})$ of taurine than that present in full-term and preterm human milk (17) was provided. The second study provided the same amount of taurine as in the present study but it can be faulted for the small number 
(five) of subjects and for the fact that they were studied over an extended period of time. It should also be noted that the fatty acid composition of the formula used in previous studies contained proportionately higher quantities of C14:0, C16:0, and C18:0. These fatty acids require a higher concentration of bile acids and presumably of physiologically available tauroconjugates to achieve the results reported herein. Perhaps a further critical aspect concerns the methodology for fat analysis. The one step direct transesterification procedure prior to $\mathrm{GC}$ analysis (24) circumvents all extraction procedures and is much more precise then the classical techniques used in the two other studies.

By 1 month of age, preterm infants fed a taurine-free formula have a predominance of glycine conjugates while those on a taurine-supplemented regimen have a glycine/taurine ratio of bile acid conjugates similar to that of infants on human milk (8). Although the glycine/taurine pattern of conjugation was not measured in the present study, it can be presumed that a predominance of taurine conjugates resulted from the supplementation especially since the concentration used, $40 \mu \mathrm{mol} / \mathrm{dl}$, is the one found in preterm human milk (17). The amount of taurine needed to conjugate bile acids is small $( \pm 5 \%)$ in relationship to the total body pool (33) which is regulated by the kidney (1). Nevertheless the hepatic pool size of taurine closely influences the bile acid conjugation pattern which in turn is dependent on dietary intake (12). The greater than 100 -fold increase in urinary taurine excretion in babies supplemented with taurine contrasts with the hypotaurinuria of the infants fed the premature formula without added taurine and suggests that a shift in the conjugation pattern of bile acids must have resulted from taurine supplementation.

A previous study did not show that taurine supplementation modified bile acid kinetics or their intraluminal concentrations (29). The improvement noted in fat absorption suggests that the shift in the conjugation pattern in favor of taurine conjugates probably improved the intraluminal phase of fat digestion and absorption. Because of the higher pKa values of glycoconjugates, it is possible that a larger percentage of glycoconjugates than tauroconjugates would precipitate out at an acid $\mathrm{pH}$. As a result, they would not be physiologically available to form micelles with lipolytic products. This may be particularly critical in preterm babies who are known to have defective exocrine pancreatic function (34). It is true that a recent in vivo study in adults with intestinal resection has failed to show that taurine supplementation decreased duodenal bile acid precipitation or improved the percentage of lipids in micellar solution (35). However, it should be noted that fat absorption was not studied and that none of these subjects had intraluminal bile acid deficiency $(<4 \mathrm{mmol} /$ liter) which is documented in more than $50 \%$ of preterm infants studied at 1 month of age (29).

Although glycine conjugates are capable of dispersing more lipids than tauroconjugates they are reabsorbed to a greater extent by passive diffusion in the jejunum (14). This could compromise micellar solubilization in the lower small bowel, a reserve area for fat absorption. The lower small bowel is recruited for absorption whenever bile acid deficiency exists or when large amounts of fat overcome the digestive-absorptive capacity of the upper jejunum (36). An indication that taurine possibly improved the shuttle of digested fat between the bulk water phase and the absorptive surface (37) is derived from the data on the fecal sequestration of individual fatty acids. The response to taurine was modest for the coefficient of absorption of unsaturates when compared to the saturates. Because of their poor solubility in water, the latter require a higher concentration of bile acids to be incorporated into micelles: furthermore saturated fatty acids require a greater length of intestine to be absorbed (38). The percentage reduction of fatty acid loss for myristic, palmitic, and stearic acid increased as their individual aqueous solubility decreased suggesting that tauroconjugates were available to form micelles with fatty acids which had escaped absorption in the upper jejunum.
In summary, this study has shown that taurine supplementation of premature formulas improves the coefficient of fat absorption, particularly that of those fatty acids which, because of their lack of polarity, require larger concentrations of bile acids and a longer length of intestine to be absorbed. Taurine supplements were recently found to decrease steatorrhea (7) and to improve postprandial chylomicronemia in cystic fibrosis (39), the present study suggests that this "conditionally essential" nutrient also has a place in the formulas designed for preterm infants.

Acknowledgment. The authors thank Mrs. D. St-Cyr Hudt for excellent secretarial assistance.

\section{REFERENCES}

1. Hayes KC, Sturman JA 1981 Taurine in metabolism. Ann Rev Nutr 1:401425

2. Chipponi JX, Bleier JC, Santi MT, Nudman D 1982 Deficiencies of essential and conditionally essential nutrients. Am J Clin Nutr 35:1112-1116

3. Knopf K, Sturman JA, Armstrong M, Hayes KC 1978 Taurine: an essential nutrient for the cat. J Nutr 108:773-778

4. Sturman JA, Wen GY, Wisniewski HM, Neuringer MD 1984 Retinal degeneration in primates raised on a synthetic human infant formula. Int $\mathbf{J}$ Dev Neurosci 2:121-129

5. Geggel HS, Ament ME, Heckenlively JR, Martin DA, Kopple JD 1985 Nutritional requirement for taurine in patients receiving long-term parenteral nutrition. N Engl J Med 312:142-146

6. Sheikh K 1981 Taurine deficiency and retinal defects associated with small intestine bacterial overgrowth. Gastroenterology 80:1363(abstr)

7. Darling PB, Lepage G, Leroy C, Roy CC 1985 Effect of taurine supplements on fat absorption in cystic fibrosis. Pediatr Res 19:578-582

8. Järvenpää AL 1983 Feeding the low-birth weight infant. IV. Fat absorption as a function of diet and duodenal bile acids. Pediatrics 72:684-689

9. Järvenpää AL, Niels C, Raiha R, Rassin DK, Gaull GE 1983 Feeding the lowbirth-weight infant. I. Taurine and cholesterol supplementation of formula does not affect growth and metabolism. Pediatrics 71:171-178

10. Okamoto E, Rassin DK, Zucker CL, Salen GS, Heird WC 1984 Role of taurine in feeding the low-birth-weight infant. J Pediatr 104:936-940

11. Gaull GE 1982 Taurine in the nutrition of the human infant. Acta Paediatr Scand [Suppl]296:238

12. Hardison WGM 1978 Hepatic taurine concentration and dietary taurine as regulators of bile acid conjugation with taurine. Gastroenterology 75:71-75

13. Rassin DK, Gaull GE, Järvenpää AL, Raiha NC 1983 Feeding the low-birthweight infant. II. Effect of taurine and cholesterol supplementation on amino acids and cholesterol. Pediatrics 72:677-683

14. Small DM 1971 The physical chemistry of cholanic acids. In: Nair PP, Kritchevsky D (eds) The Bile Acids. Plenum Press, New York pp 247-354

15. Krag E, Phillips SF 1974 Active and passive bile acids absorption in man. $J$ Clin Invest 53:1686-1694

16. Watkins JB, Ingall D, Szczepanik P, Klein PD, Lester R 1973 Bile salt metabolism in the newborn: measurement of pool size and synthesis by stable isotope technique. N Engl J Med 288:431-434

17. Lepage G, Bouglé D, Kien LC, Lepage D, Dallaire L, Darling P, Roy CC 1984 The composition of preterm milk in relation to the degree of prematurity. Am J Clin Nutr 40:1042-1049

18. Fitzhardinge PM 1975 Early growth and development in low-birth-weight infants following treatment in an intensive care nursery. Pediatrics 56:162172

19. Gross SJ, David RJ, Bauman L, Tomarelli RM 1980 Nutritional composition of milk produced by mothers delivering preterm. J Pediatr 96:641-644

20. Kien LC, Summers JE, Stetina JS, Heimler R, Grausz JP 1982 A method for assessing carbohydrate energy absorption and its application to premature infants. Am J Clin Nutr 36:910-916

21. Reichman B, Chessex P, Putet G, Verellen G, Smith JM, Heim T, Swyer PR 1981 Diet, fat accretion and growth in premature infants. N Engl J Med 305:1495-1500

22. O'Brien D, Ibbott FA, Rodgerson DO 1968 Determination of creatinine in urine. In: Laboratory Manual of Pediatric Microbiochemical Techniques 4th ed. Harper \& Row Publishers Inc, Hagerstown, MD, pp 114-116

23. Blom W, Huijmans J 1985 Differential diagnosis in inherited amino acid metabolism or transport disorders. Sci Tools 32:1

24. Lepage G, Roy CC 1986 Direct transesterification of all classes of lipids in a one-step reaction. J Lipid Res 27:114-120

25. Winers RJ 1971 Statistical Principles in Experimental Design. McGraw-Hill Book Co. New York, pp 210-218

26. Alemi B, Hamosh M, Scanlon JW, Salzman-Mann C, Hamosh P 1981 Fat digestion in very low-birth weight infants: effect of addition of human milk to low-birth weight formula. Pediatrics 68:484-489

27. Atkinson SA, Bryan MA, Anderson GH 1981 Human milk feeding in premature infants: protein, fat and carbohydrate balances in the first two weeks of life. J Pediatr 99:617-624

28. Reichman B, Chessex P, Verellen G, Putet G, Smith JM, Heim T, Swyer PR 
1983 Dietary composition and macronutrient storage in preterm infants. Pediatrics 72:322-328

29. Watkins JB, Järvenpää AL Szczepanik van Leeuwen P, Rassin DK, Gaull G, Raiha NCR 1983 Feeding the low birth weight infant: V Effects of taurine, cholesterol and human milk on bile acid kinetics. Gastroenterology 85:793800

30. Chapell JE, Clandinin MT, Kearney-Volpc C Richman B. Swyer PW 1986 Fatty acid balance studies in premature infants fed human milk or formula: Effect of calcium supplementation. J Pediatr 108:439-448

31. Finley AJ Davidson M 1980 Bile acid excretion and patterns of fatty acid absorption in formula-fed premature infants. Pediatrics 65:132-138

32. Watkins JB, Bliss M, Donalson RM. Sester R 1974 Characterization of newborn fecal lipids. Pediatrics 53:511-515

33. Sturman JA, Hepner GW, Hofmann AF. Thomas PJ 1975 Metabolism of ${ }^{35} \mathrm{~S}$ taurine in man. J Nutr 105:1206-1214

34. Zoppi G, Andreotti G, Pajno-Fenrara F. Njai DM. Gaburro D 1972 Exocrine pancreas function in premature and full-term neonates. Pediatr Res 6:880886

35. Fitzpatrick WJF. Zentler-Munro PL, Northfield TC 1986 Ileal resection: effect of cimetidine and taurine on intrajejunal bile acid precipitation and lipid solubilisation. Gut 27:66-72

36. Williamson RCN 1978 Intestinal adaptation. N Engl J Med 298:1393-1402. $1443-1450$

37. Westergaard H, Dietschy JM 1976 The mechanism whereby bile acid micelles increase the rate of fatty acid and cholesterol uptake into the intestinal mucosal cell. J Clin Invest 58:97-108

38. Ockner RK, Pittman JP, Yager JL 1972 Differences in the intestinal absorption of saturated and unsaturated long chain fatty acids. Gastroenterology 62:981991

39. Belli DC, Levy E, Darling P. Leroy C, Lepage G, Giguère R, Roy CC 1986 Taurine improves the absorption of a fat meal in cystic fibrosis. Pediatrics (in press) 